\title{
Design in Evaluation: Reflections on Designing for Children's Technology
}

\author{
Emanuela Mazzone \\ ChiCl Group \\ University of Central Lancashire \\ Preston PR1 2HE (UK) \\ +44 1772895152 \\ EMazzone@uclan.ac.uk
}

\author{
Diana Xu \\ Chicl Group \\ University of Central Lancashire \\ Preston PR1 2HE (UK) \\ +44 1772895301 \\ YFXu@uclan.ac.uk
}

\author{
Janet C Read \\ ChiCl Group \\ University of Central Lancashire \\ Preston PR1 2HE (UK) \\ +44 1772893285 \\ JCRead@uclan.ac.uk
}

\begin{abstract}
This paper reflects on the design value that emerges from evaluation methods used in the field of child computer interaction.

The work is based around an evaluation study of a tangible game prototype for children. The prototype and the evaluation techniques used are described. The authors provide a reflection on the analysis of results from one of the methods and use this analysis to propose a direct connection with design tools.
\end{abstract}

\section{Categories and Subject Descriptors}

H.5.2 User Interfaces - Evaluation/Methodology, Theory and methods, User-centred design; I.3.6 Methodology and Techniques - Interaction techniques;

\section{General Terms}

Performance, Design, Experimentation, Human Factors, Theory, Verification.

\section{Keywords}

User-Centred approach, Children technology design, Evaluation methods, Design methods.

\section{INTRODUCTION}

The term 'design' in a Human-Computer Interaction context can assume many different meanings and perspectives depending on the design goals and resources.

[14] defines design as three main comprehensive connotations:

- The redesign to solve problems on existing systems;

- The development of new system to support current activities;

- The envisioning of novel application that could support emerging human activities.

This latter emergent level of design has been addressed by several researchers within the context and description of future technologies [22,21] and it aims at freeing the creativity from constraints and the biases due to experience and background culture. In this creative process users are considered to play a

(C) Emanuela Mazzone, Diana Xu, Janet Read 2007

Published by the British Computer Society

Volume 2 Proceedings of the 21st BCS HCI Group Conference

HCI 2007, Lancaster University, 3-7 September 2007 significant role.

From a User-Centred approach, it is agreed to refer to the whole design process as iterations of different cycles from concepts generation to product prototyping, evaluation and implementation. In traditional approaches [19], users were consulted mainly at the end of the process to evaluate and validate an almost-finished product. It is now becoming common practice to include users at any stage of the progress, according to different techniques and purposes.

Following the same principle, the tradition of involving children when designing and producing technology for them as users has being growing in the last decade or so [i.e. hence the origin of Interaction Design and Children conferences]. Studies have classified their roles as users, testers, informants or design partners [6], according to the degree of contribution and the stage of their intervention throughout the design process.

Within these broad categories many studies have developed, through investigating and experimenting new methods or validating and adapting existing ones [12]. At the same time, many principles and guidelines have been derived and produced from a comprehensive tradition of research in the field.

Investigation of methods, as seen in [10], normally focuses on a specific context or design purpose.

Given its broad sense of encompassing the whole process, in this paper the meaning of the term 'design' refers to the specific phase of concept generation which feed the development of the product or its prototypes.

With regards to the design phase, two of the most interesting ways that allow children to be significant contributors to the design process are informant design and cooperative enquiry. The term informant was first used by [20] and describes a process by which children contribute their ideas to the overall design of a product but are not considered as design partners. Participatory design and cooperative enquiry [7], which are closer to the ideal of design partner, suggest greater equality between children and adult designers, together with more involvement by the children, and a democracy of ideas.

Many difficulties still need to be overcome in the application of informant and cooperative design methods, and several studies are looking at novel approaches to get more value from sessions with children.

On the other hand, concerning the evaluation phase, methods involving children as users can be divided into two main categories [3]: inquiry, which aim to elicit information and opinions by questioning the users after their interaction with the system; and observational methods, carried out during the user 
performance. This last category includes techniques like Think Aloud protocol, Constructive Interaction [15], Cooperative Evaluation, Peer-Tutoring [9] and Problem Identification Picture Cards (PIPC) method [4].

This paper refers to a study [23] designed with the intention of determining the ease of use and effectiveness of four combined user-based evaluation methods to discover problems and detect flaws when children interact with tangible technology.

After a brief description of the four methods (two for the observation and two for the inquiry) chosen for the evaluation study of the two tangible game prototypes, this paper will briefly present the study and then focus its reflection on the results of the two inquiry methods.

\section{METHODS}

The two methods selected for the observation during the user activities were: Co-discovery, Peer Tutoring.

Co-discovery (or constructive interaction) intends to let the users collaborate with each other in order to learn how to interact with the system. This method is supposed to facilitate discussion between the subjects and provide information on their understanding of the interaction [16]. It is proved to be more effective in encouraging children verbalizing their thoughts than simply trying to prompt them to think aloud while performing the task $[2,15]$.

In the Peer Tutoring method [9], children teach their friends how to use the technology after they have interacted with the product. This technique is useful to see how children have understood the product and how they are able and willing to communicate this to their peers

The inquiry methods employed after the user tasks were Questionnaire and Drawing Intervention [24].

When it comes to children, questionnaires are a useful and quick source of information [17], but they still need thoughtful planning when designing them, paying particular attention to the length, language or other implicit biases that are likely to compromise the response.

Drawing Intervention is a novel and more informal evaluation method, inspired by the natural school classroom settings. According to it, after the children completed the tasks, they draw anything related to what they have done. Drawing is an activity they are very familiar with and normally used in classroom to express themselves. The rationale behind this method is that children feel more relaxed and less inhibited to talk to each other when drawing while the researchers are able to discover their real thoughts about their experiences.

\section{THE STUDY}

The study took place in an educational suite of a local primary school, involving 24 children from a Year 5 (aged 9-10) classroom. The children participated to the activities during a normal school day.

Groups of four children at a time were brought into the room and asked to play together the two games set up for the study. Following the games, they were asked to sit at a table and fill in the evaluation sheet, consisting either of the questionnaire or of the Drawing Intervention. Each group session lasted between 15 and 20 minutes.

The two games were based on a very simple principle, which was to interact with a tangible interface to find 8 correct items amongst 16 shuffled pieces. The team to gather more food items would win the game. Two prototypes were created, one for the tabletop and one for the room. Both implementations were coded in Visual Basic and used the Phidgets ${ }^{\circledR}$ technology.

The game was designed to be played across two different dimensions of interaction, both involving a screen displayed feedback. One, called TableTop (Figure 1.a), was constrained to a wooden board and used light sensors, the other, Box-based (Figure 1.b), involved loose pieces that could be located anywhere in the space, in this case they were scattered in a box together with decorative objects and tagged with RFID technology. While this paper focuses on a specific aspect of the results of two of the evaluation methods, a detailed description of the games can be found in [23].

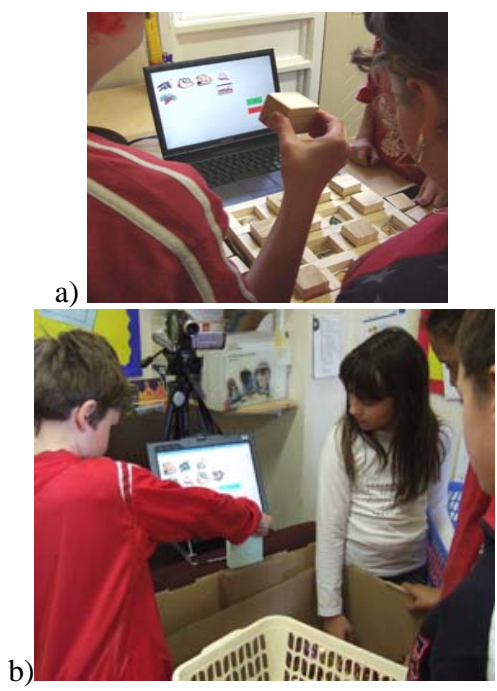

Figure 1. the groups playing at the games: TableTop (a) and box-based (b)

To allow a comprehensive combination of the evaluation methods, the first group was asked to have a turn at the games and learn to play them, while they were observed during the Co-discovery approach. In this instance of play, the children were asked to split spontaneously in two teams of two, playing one team against the other.

After both game had been played, the children sat at a table to complete a paper evaluation sheet (Figure 2).

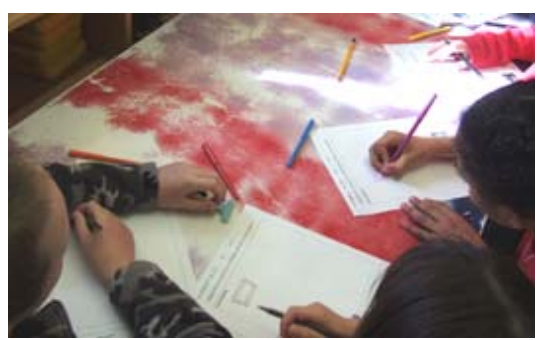

Figure 2. Children completing evaluation sheets

On completing the session, one of the two pairs of children (randomly chosen by tossing a coin) was sent back to the classroom while the other pair was asked to come back with two new class mates, to re-form another group of four children. According to a Peer tutoring approach, the two children (experts) who have played before guided the second two (novices) in the play of the game, based on their previous understanding.

For the inquiry methods evaluation, two paper forms, Drawing Intervention and questionnaire were alternated in order to give 
the 'peer tutors' the chance to complete a different one each time.

At this point all the four children were then sent back to the classroom and a new group of four children entered the room to start again the process.

\section{DISCUSSION}

Two researchers conducted the study, one mainly interacting with the children, while the other focussing more on the observation, taking notes and video recording the playing.

For the purpose of this paper, the focus will be on the analysis of the two inquiry methods.

Being a study about the effectiveness of evaluation methods in discovering problems when interacting with technology, the selected inquiry methods were designed in order to make the children focus on the same question through two different approaches.

In both cases children were asked to think of what they would like to add and to change about the game they had just been playing. In the questionnaire sheet they had some blank space to write add-ons and changes for each of the games, in the Drawing Intervention sheet they had one blank box to draw anything they wanted to add and change on one or both of the games. It has been shown that children find it more difficult to express their ideas with words while drawing is a more effective tool for communication for them [6] and so it was expected that these methods would produce different results.

It was also supposed that the amount of $\mathrm{i}$

deas that resulted from the Drawing Intervention would be greater from that gathered from the questionnaires, and this was the case. In addition, the Drawing Intervention activity provided results that were also richer in details and creativity than those from the questionnaire. For example, the suggestions written in the questionnaire mainly concerned addition of sound/music feedback or change in the topic of the pictures. In many cases they also answered that they did not want to add or change anything to the actual game. On the other hand, all the children that had the chance to draw their thoughts did offer more than one idea and in more than one design aspect (content, multimedia feedback, mode of interaction, input modality).

Furthermore, in the same way as the children that completed just one of the evaluation exercises, even the children that had the chance to complete both the questionnaire and the Drawing Intervention (those who had tutored in the peer tutoring activity) responded to the same question with a completely different perspective, being much more imaginative and detailed in the drawing activity compared to the writing one. Figure 3 gives an idea of the difference in amount of information given by the same child in the two different methods.

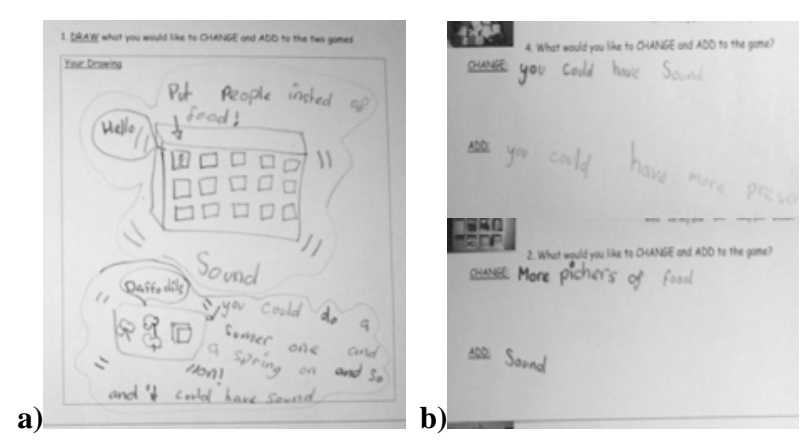

Figure 3. an example of the output of Drawing Intervention

(a) and Questionnaire (b) from the same child

\section{CONCLUSION}

In many cases drawing has been shown to be useful as a form of low-tech prototyping to allow children (and not only children) to envision and visualise their ideas [6, 21, 11, 22]. In the case described in this paper, drawing proved to be also a very effective evaluation tool, providing feedback on children's likes and dislikes of the specific technology as well as information about their interactions with the technology.

Although evaluation was the main purpose for this specific study, the method referred to as Drawing Intervention in this study acted as a design tool at the same time. The output from the Drawing Intervention can be considered not only useful for the evaluation of the game but at the same time it provides potential requirements for the following iteration of the design cycle.

Since evaluation and not design was the main goal of the study, no constraints were given to the children in that respect. Therefore, in the case of using these results as design requirements, they would contribute towards an open-ended or emergent, future technology approach [14,21,22].

Nevertheless, the outputs of the drawing activity have added value in term of design and requirements gathering as a first hand insight and a rich source of information of the children concept and understanding of the technology interaction.

This study has provided several ideas for further work. The first one being the redesign of the tangible game including children design contributions concerning content, interactive functionalities and different type of multimedia inputs and outputs. Other directions to take could be to examine other evaluation methods and investigate their potential for use in design; or also to explore if design methods can similarly be used for evaluation.

A study is currently ongoing to discover new design methods for use with children and this work is contributing to a greater understanding of designing for and with children of several ages.

\section{ACKNOWLEDGMENTS}

Our thanks go to the children and staff of Hesketh with Becconsall All Saints C.E. Primary School (UK), who participated in the study, and to $\mathrm{J}$ and $\mathrm{J}$ who kindly worked on building the wooden TableTop prototype.

\section{REFERENCES}

[1] Alborzi, H., A. Druin, J. Montemayor, M. Platner, J. Porteous, et al. "Designing StoryRooms: interactive storytelling places for children”. ACM SIGCHI 2000 
Symposium on Designing Interactive Systems (Brooklyn, 2000), ACM Press.

[2] Als, B.S., Jensen, J.J., and Skov, M.B. Exploring verbalization and collaboration of constructive interaction with children, in Proceedings of Interact Conference (Rome, Italy, 2005)

[3] Barendregt, W., Evaluating fun and usability in computer games with children, Ph.D. Thesis, Eindhoven University of Technology, Eindhoven, 2006

[4] Barendregt, W. and M.M. Bekker. Development and Evaluation of the Picture Cards Method in Proceedings of Interact 2005, Tenth International Conference on HumanComputer Interaction 2005. Rome, Italy

[5] Borgers, N., J. Hox, and D. Sikkel, Response Effects in Surveys on Children and Adolescents: The Effect of Number of Response Options, Negative Wording, and Neutral Mid-Point. Quality and Quantity, 38(1): 2004.17 33.

[6] Druin, A., Ed. “The Design of Children's technology”, Morgan Kaufmann Publishers, Inc. 1999

[7] Guha, M.L., Druin, A., Chipman, G., Fails, J.A., Simms, S., Farber, A. Working with Children as Technology design partners, Communications of the ACM, January 2005, vol.48, no.1, special issue Interaction Design and Children, 39-42

[8] Hanna, E., et al., The Role of Usability Research in Designing Children's Computer Products, in The Design of Children's Technology, A. Druin, Editor. Morgan Kaufmann: San Francisco. (1999). 4-26.

[9] Hoysniemi, J., P. Hamalainen, and L. Turkki, Using peer tutoring in evaluating the usability of a physically interactive computer game with children. Interacting with Computers, 2003. 15(2): p. 203-225

[10] Jensen, J., Skov, M. A Review of Research methods in Children's Technology Design, in Proceedings of IDC Conference 2005 (Boulder, USA 2005)

[11] Kelly,R., Mazzone,E., Horton, P., Read, J. "Bluebells: A Design Method for Child-Centred Product Development”. in Proceedings of NordiCHI 2006 (Oslo, 2006), ACM Press.

[12] Markopoulos, P and Bekker, M. (2003b) On the assessment of usability testing methods for children. Interacting with Computers, 15(3), 227-243.
[13] Markopoulos, P. and M. Bekker. How to compare usability testing methods with children participants. in Proceedings of Interaction Design and Children'02. (Eindhoven, Netherlands, 2002)

[14] Marti, P., Rizzo, A. Levels of design: from usability to experience, in Proceedings of HCI International (Crete, 2003) Lawrence Erlbaum Associates

[15] Miyake, N. Constructive Interaction and the Iterative Process of Understanding. Cognitive Science, vol. 10(2), 1986. pp. 151 -- 177

[16] Nielsen, J. Usability Engineering, Morgan Kaufmann Publishers Inc., San Francisco, CA, 1993

[17] Read, J.C. and S.J. MacFarlane. Using the Fun Toolkit and Other Survey Methods to Gather Opinions in Child Computer Interaction. in Interaction Design and Children, 2006 (Tampere, Finland, 2006) ACM Press.

[18] Read, J. C., MacFarlane, S. J., and Casey, C. What's going on? : Discovering what Children Understand about Handwriting Recognition Interfaces, in Proceedings of IDC2003 (Preston, England, 2003) ACM Press

[19] Rubenstein, R. and H. Hersh, "The Human Factor: Designing Computer Systems for People”, Digital Press, 1984.

[20] Scaife, M., \& Rogers, Y. Kids as informants: Telling us what we didn't know or confirming what we knew already. A. Druin (Ed), The design of children's technology, Morgan Kaufmann, San Francisco, CA, 1999, 27-50.

[21] Stringer, M., Harris, E., and Fitzpatrick, G. Exploring the space of near-future design with children. In Proceedings of NordiCHI2006 (Oslo, Norway, 2006)

[22] Vavoula, G. N., Sharples, M., \& Rudman, P. D. Developing the 'Future Technology Workshop' method. In Proceedings of IDC 2002, ACM Press (2002), 65-72

[23] Xu, D., Mazzone, E., Read, J.C. Designing and Testing a Tangible Interface Prototype for use in the Evaluation Study with Children in Proceedings of Interaction Design and Children 2007, Denmark, ACM Press (2007)

[24] Xu, D., Read, J.C., Mazzone, E., MacFarlane, S., Brown, M. Evaluation of Tangible User Interfaces (TUIs) for and with Children - Methods and Challenges in Proceedings of International HCI Conference 2007, (Beijing, China, 2007) LNCS, Springer (in press) 